\title{
Esophageal Obstruction in Buffaloes (Bubalus bubalis) Resulting from the Ingestion of Potato Tubers
}

\author{
Mohamed Shokry ${ }^{1, *}$ and Abdelhaleem Elkasapy ${ }^{2}$ \\ ${ }^{1}$ Department of Veterinary Surgery, Faculty of Veterinary Medicine, Cairo University, Giza, Egypt \\ ${ }^{2}$ Department of Veterinary Surgery, Faculty of Veterinary Medicine, Benha University, Benha, Egypt
}

\begin{abstract}
Total 32 emergency cases of buffaloes with esophageal obstruction resulting from the ingestion of potato tubers during their grazing are described. Treatment comprised immediate rumen trocarisation by a $14 \mathrm{~g}$ syringe, premedication with IM xylazine $(0.05 \mathrm{mg} / \mathrm{kg})$, and passing a designed stout flexible tube to dislodge the obstruction to the rumen. The results were $100 \%$ successful recovery without any complications.
\end{abstract}

Keywords: Esophageal obstruction, choke, potato, trocarisation, probing.

\section{INTRODUCTION}

Potato crop in Egypt is at the front of export vegetable crops, as annually an estimated quantity of 400,000-450,000 tons is exported (Egyptian Agriculture Research Center/ Bulletin 940/2005). The weather conditions in Egypt allow the potato crop to be cultivated for 7 consecutive months from mid-August to mid-February while harvesting the crop from the end of October. With the abundance of this crop, farmers cannot fully harvest it, and this leads to the spread of potato tubers alongside the cultivated paths as the harvest process needs to remove green clusters from the ground 24-48 hours before the harvest process to help to show the tubers outside (Figure 1). Such a preliminary process helps harden the tubers and makes them more able to bear harvesting and transportation. The spread of green nuggets over large areas encourages livestock to escort their owners to ingest them, including potato tubers with consequent health hazards of mass attack of emergency esophageal choke, which may lead to death or emergency slaughter if no prompt veterinary intervention is performed. These cases necessitate a prompt clinical intervention to save the animals with the simplest available tools and reduce losses.

Esophageal obstruction (Choke) is an emergency clinical condition in large ruminants caused by largesized foodstuff, foreign bodies, trichobezoars (composed of animal hair and vegetable fiber), or esophageal granulomas [1-3]. Esophageal obstructions commonly occur at the pharynx, the cranial aspect of the cervical esophagus, or the thoracic inlet [4].

*Address correspondence to this author at the Department of Veterinary Surgery, Faculty of Veterinary Medicine, Cairo University, Giza, Egypt;

E-mail: mshokry@cu.edu.eg
Diagnosis depends on the history of eating particular foodstuff and signs such as salivation, restlessness, retching, external palpation, and tympany, which may be fatal [5]. Treatment comprises external percutaneous esophageal massage, the passage of stomach tube or probing, endoscopic removal [6], and surgical intervention [3]. The present field study reports about the clinical management of mass cases of esophageal obstruction in buffaloes without using unnecessary invasive surgical intervention.

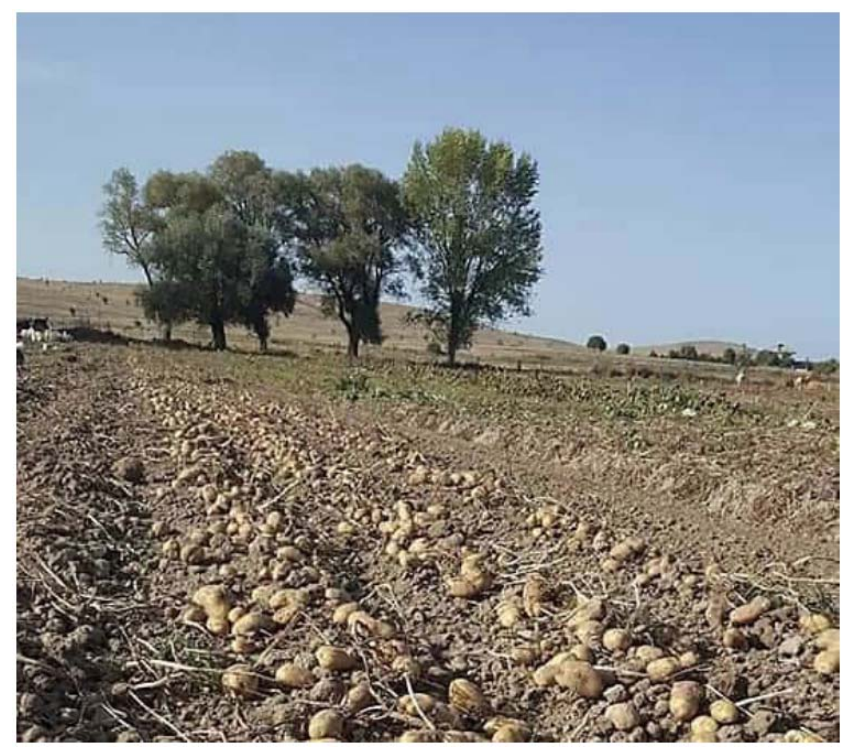

Figure 1: Cultivated paths with Potato tubers.

\section{MATERIAL AND METHODS}

\section{Case History and Clinical Signs}

The surgery clinic of the Faculty of Veterinary Medicine at Benha University was called upon to manage emergency cases of buffaloes reported with histories of profuse salivation, respiratory distress, inability to swallow, and abdominal left flank distension 
resulting from the ingestion of potato tubers during their grazing in the nearby harvested potato fields within two months. The total number of the managed cases was 32 adult female buffaloes. Their ages were between 3 and 8 years. Most of the cases presented signs of restlessness, overstretched head, drooling saliva, intervals of coughing, respiratory distress, elevated respiratory and heart rates, frequent retching, and acute ruminal tympany.

\section{Management and Treatment}

The buffaloes were premedicated with IM xylazine $\mathrm{HCl}(0.05 \mathrm{mg} / \mathrm{kg} \mathrm{im})$ (Xylaject, Adwia Co., Egypt). Immediate rumen trocarisation by using a sterile syringe's needle $(14 \mathrm{~g})$ to minimize the trapped gases in the rumen. A hard, flexible tube, made of a silicone garden soft hose (1- inch diameter and 4-feet long) strengthened by a hard plastic PVC pipe support (3/4inch and 4- feet long), was used as a crude probing (Figure 2). The buffalo restrained in a pillar brace and gagged while an assistant was holding the tongue deviated towards the right commissure of the mouth to facilitate the passage to the pharyngeal ostium of the gullet (Figure 3). Another assistant held one end of the tube to keep it straight. The other end of the probing tube was lubricated with vegetable oil and passed through the mouth into the pharynx and then the gullet by gentle pushing to dislodge the obstruction into the rumen. The soft and flexible material of the tube allowed to work safely without hurting the surrounding tissues.

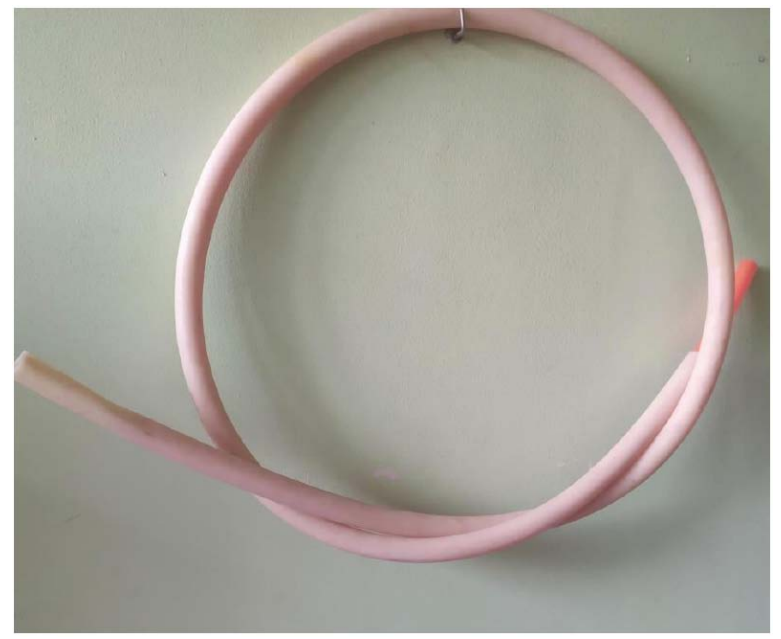

Figure 2: The designed stomach tube.

\section{RESULTS}

By using the designed tube, results were good with a success rate of $100 \%$ in the rapid treatment of esophageal obstruction with potato tubers, with excellent efficiency and without any complications, and this was reflected in the immediate return of the affected animals to normal as soon as the blocked esophagus cleared of the obstruction.

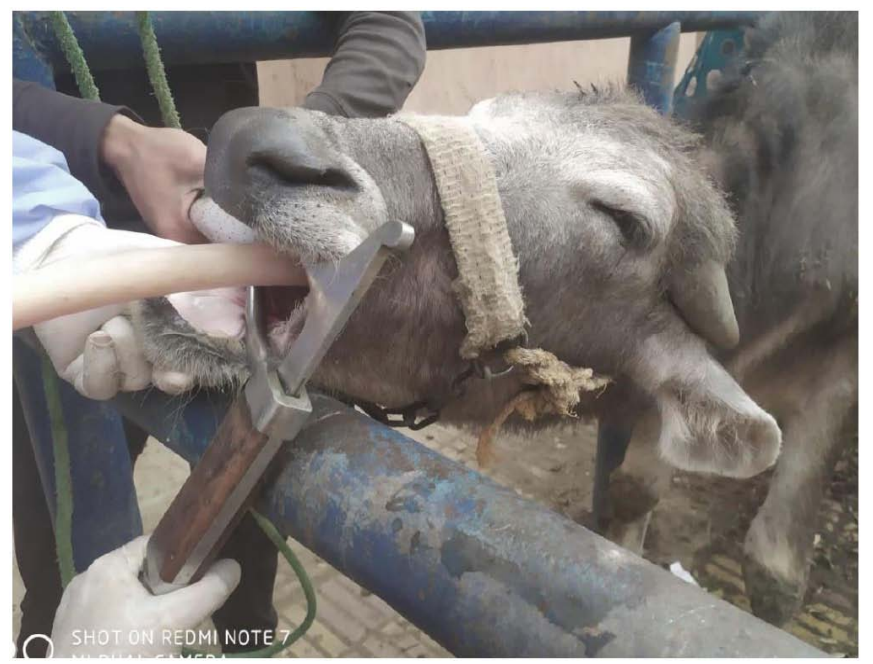

Figure 3: Passing of the tube.

\section{DISCUSSION}

Like cattle, buffaloes frequently suffer from esophageal obstruction, as they may swallow feed without appropriate chewing. Most veterinarians use a surgical intervention in such cases by removing the cause of the obstruction directly from the esophagus or by opening the rumen and removing it if it is present in the last part of the esophagus [3,5,7-9] despite surgical intervention increases costs and complications. Also, the use of traditional solid probes may cause severe complications when used roughly. The buffalo is known for its fierce nature, which escalates with the obstruction of the esophagus. Therefore, giving a dose of the drug xylazine premedication helps in calming the animal and in the relaxation of the muscles of the esophagus, which makes it easier to push it into the rumen with the use of the designed probe. It is important for the immediate trocarisation of the inflated rumen with a $14 \mathrm{~g}$ syringe's needle for successful intervention. In this report, using a soft hose with a rigid end allowed the treatment of all affected cases with high-speed recovery without any complications.

\section{CONCLUSION}

The clinical field management of choke in buffaloes with a low-cost veterinary intervention proved sufficient to rescue the affected animals without any invasive surgery. 


\section{ANIMAL RIGHT}

Animal handling and management procedures were performed according to institutional animal care and used a Cairo University CU-IACUC guidelines committee.

\section{CONFLICT OF INTEREST}

The authors declare that no conflict of interest

\section{REFERENCES}

[1] Tyagi RPS, Oesophagus SJ. In Textbook of Ruminant Surgery, $1^{\text {st }}$ ed. CBS Publishers and Distributers. New Delhi, India 1999; 192.

[2] Radostits OM, Gay CC, Hinchcliff KWA. Textbook of diseases of Cattle, Sheep, Pigs, Goats and Horses, London, UK: W.B. Saunders Ltd. 2000; 1526-1527.

[3] Marzok M, Moustafa A, El-Khodery S, Muller K. Esophageal obstruction in water buffalo (Bubalus bubalis): a retrospective study of 44 cases (2006-2013). Turkish J Vet and Animal Sci 2015; 39: 233-240.

https://doi.org/10.3906/vet-1410-4

[4] Smith BP. Large Animal Internal Medicine. $4^{\text {th }}$ Ed. St.Louis, MO, USA: Mosby 2008; 804-805.

[5] Borakhatariya D, Gadara AB. Surgical management of choke through oesophagotomy in a buffalo: A case report. The Ind J Vet Sci Biotechnol 2017; 12: 73-74. https://doi.org/10.21887/ijvsbt.v12i3.7098

[6] Krishna H, Prasad YD, Haritha GS, Sreenu M. Cervical oesophageal obstruction in a she-buffalo. Buffalo Bull 2020; 39: 501-505. http:/ kuojs.lib.kuac.th

[7] Mahesh V, Pramodh JK, Ranganath L, Amith NG, Murthy S. Clinical management of esophageal choke-A clinical study of 25 cattle. Intas Polivet 2016; 17: 607. Gale doc. No./A509322091

[8] Pund S, Chattar V, Netake P. A surgical approach for an oesophageal choke in a crossbred cow. International J Sci Environ Technol 2018; 7: 1662-1665.

[9] Kumar RV, Lakshmi ND, Veena, P Sanker P, Yasotha P. Surgical management of cervical esophageal obstruction in a buffalo: A case report. Buffalo Bull 2010; 29: 71-72.

https://doi.org/10.6000/1927-520X.2021.10.11

(C) 2021 Shokry and Elkasapy; Licensee Lifescience Global.

This is an open access article licensed under the terms of the Creative Commons Attribution License (http://creativecommons.org/licenses/by/4.0/) which permits unrestricted use, distribution and reproduction in any medium, provided the work is properly cited. 